\title{
30. LAS DISPOSICIONES DEL GOBIERNO Y LA ADMINISTRACIÓN
}

\author{
ANTONIO M. GARCÍA CUADRADO \\ Profesor Titular de Derecho Constitucional \\ Universidad de León
}




\title{
30. LAS DISPOSICIONES DEL GOBIERNO Y LA ADMINISTRACIÓN
}

\author{
POR \\ ANTONIO M. GARCIA CUADRADO \\ Profesor Titular de Derecho Constitucional \\ Universidad de León
}

1. Desde la entrada en vigor de la Constitución de 1978 es cada vez mayor la preocupación entre los constitucionalistas por los problemas de fuentes, como lo demuestra el progresivo aumento de investigaciones sobre estos temas por parte de los estudiosos de la Constitución, tanto o más incluso, últimamente, que de los administrativistas .

Sin embargo, no todos los temas de fuentes formales están recibiendo un mismo tratamiento por la doctrina. En concreto existe un aspecto que a mi juicio se está descuidando peligrosamente. Me refiero a la ordenación de las fuentes emanadas del Poder Ejecutivo, es decir, del Gobierno y de los órganos superiores de la Administración Central del Estado. Creo que la problemática en este campo no se reduce, ni mucho menos, al estudio de la potestad reglamentaria y de las relaciones ley-reglamento, pues hoy es preciso un estudio a fondo, y no sólo teórico sino contrastado con la realidad que cada dia aparece en el Boletín Oficial del Estado, de las categorias formales de "Real Decreto", "Orden Ministerial», etc.

En esta ponencia me propongo demostrar tres cosas:

1. ${ }^{a}$ Que actualmente, en todo el tema de las disposiciones dictadas por el Gobierno y la Administración, la práctica no se ajusta a las previsiones legales, entre otras razones porque éstas han quedado manifiestamente anticuadas y además no responden a ciertas exigencias constitucionales sobre relaciones de organización. 
2. Que sería muy conveniente una reforma sustancial del régimen jurídico de estos instrumentos dispositivos en el sentido que se propone en esta ponencia: acomodando la jerarquía jurídica de las disposiciones a la jerarquía orgánica de los autores de las mismas.

3. Que las líneas fundamentales de este nuevo régimen jurídico deben aparecer plasmadas en la propia Constitución en lugar de permitir que sea regulado en bloque por la legislación ordinaria.

2. Veamos, en primer lugar, cuál es la situación actual de esta cuestión, tanto en el plano normativo como en el campo práctico.

A. Con respecto al régimen normativo de rango constitucional, lo primero que se observa es que la Constitución dejó prácticamente una libertad total al legislador. Sólo algunos preceptos constitucionales referidos a las relaciones internas en el Ejecutivo y a las funciones del Rey nos proporcionan pistas indirectas sobre el tema que nos ocupa.

- "Corresponde al Rey ...f) Expedir los decretos acordados en el Consejo de Ministros..." (art. 62); por tanto la disposición superior dentro de las que proceden del Ejecutivo ha de ser el Real Decreto, firmado por el Rey (que siguiendo la tradición habla en nombre propio: "Dispongo»).

- Los actos del Rey "estarán siempre refrendados ... careciendo de validez sin dicho refrendo...» (art. 56.3); en concreto lo estarán, para lo que ahora nos interesa, por el Presidente del Gobierno o por un ministro (art. 64.1); se mantiene así una vieja tradición, quizá una antigua convención constitucional: el Real Decreto aparece refrendado por el ministro que lo propone al Gobierno o por el Presidente en casos especiales (que tenga rango de ley: Real Decreto-ley o Real Decreto legislativo, que se trate de una decisión política que la Constitución atribuye al Presidente y no al Gobierno, como la disolución de las Cortes, o que sea una decisión que afecta a varios Ministerios o fue iniciativa del Presidente).

- El Rey no es ya titular de la función ejecutiva ni de la potestad reglamentaria, sino que la Constitución declara al Gobierno como titular de ambas (art. 97); Hasta tal punto, que el Rey ya no preside nunca el Gobierno, sino, sólo a iniciativa del Presidente, las sesiones del Consejo de Ministros. 
- Los ministros son nombrados y relevados por el Rey (mediante Real Decreto, se entiende) a propuesta del Presidente del Gobierno (62.e. y 100), cuyo carácter de órgano superior dentro del Consejo resulta evidente, puesto que además "dirige la acción del Gobierno y coordina las funciones de los demás miembros" (art. 98.2), los cuales, sin embargo, tienen "competencia y responsabilidad directa" en su gestión.

B. A nivel legislativo, al no existir todavía el Estatuto del Gobierno previsto en el art. 98.4 de la Constitución, sigue vigente casi en su integridad lo dispuesto en el Título III de la Ley de Régimen Jurídico de la Administración del Estado (Texto refundido de 26 de julio de 1957) sobre las "Disposiciones y resoluciones administrativas". En particular conviene destacar ahora:

- Que «Las disposiciones normativas de carácter general se ajustarán a la siguiente jerarquía normativa: Primero, Decretos; Segundo, Órdenes acordadas por las Comisiones Delegadas del Gobierno; Tercero, Órdenes ministeriales; Cuarto, disposiciones de autoridades y órganos inferiores según el orden de su respectiva jerarquía" (art. 23.2).

- Con las debidas adaptaciones puede considerarse vigente también el art. 24 que determina cuándo una decisión del Ejecutivo deberá adoptar la forma de Decreto (hoy Real Decreto) y cuándo podrá ser aprobado por Orden Ministerial: “Adoptarán la forma de Decreto las disposiciones generales no comprendidas en los arts. 10 y 12 de la Ley de Cortes (hoy la referencia debe entenderse a todas las reservas constitucionales de ley) y las resoluciones del Consejo de Ministros, cuando así lo exija alguna disposición legal, y serán firmadas por el Jefe del Estado y refrendadas por el ministro a quien correspondan.

En conclusión: la regulación normativa de estas materias es incompleta, insuficiente, a veces contradictoria con preceptos constitucionales (o al menos con principios implícitos) y desde luego necesitada de una actualización, pero sobre todo de unos principios claros sobre el papel que ocupa cada órgano del Ejecutivo y por tanto el que corresponde a las disposiciones por él dictadas.

C. Esta afirmación se ve confirmada, a mi juicio, con un análisis un poco detallado del Boletín Oficial del Estado. En este sentido, se echa 
en falta un estudio de conjunto que dejando al margen las concepciones doctrinales nos facilite información real sobre cómo se utilizan en la práctica las categorías formales de "Real Decreto", "Orden de Comisión", etc. Por mi parte puedo aportar algunos datos que considero de gran interés:

- Desde los años cuarenta hasta 1983 el número de Decretos permaneció prácticamente invariable en torno a los 3.000 anuales (entre 2.800 y 3.400 según años), pero desde entonces ha ido disminuyendo considerablemente y en la actualidad el Rey firma en torno a 1.500 Reales Decretos cada año (sin duda a causa de la descentralización política, pero también de la desconcentración de funciones, también ordenada por nuestra Constitución en el art. 103.1). De ellos, cerca de 300 contienen disposiciones generales, es decir, "reglamentos" en sentido amplio.

- Cada año la Administración Central del Estado dicta en torno a un millar de reglamentos, de los que aproximadamente la mitad se aprueban por medio de Orden Ministerial, algo menos de un tercio lo son por Real Decreto y el resto por Resolución, Instrucción o Circular de Subsecretaría, Secretaría de Estado o Dirección General 1 .

- Existen muy pocas Órdenes de Comisiones Delegadas del Gobierno, aunque de hecho es difícil saber cuáles lo son, pues su apariencia es muy similar a la de las Órdenes ministeriales ${ }^{2}$, resultando en ocasiones

1 No considero aquí disposición general a la publicación de un convenio colectivo. Entre dos y tres centenares de ellos se publican al año en el BOE mediante resolución de una Dirección General. Por otra parte, los datos están referidos sólo a las disposiciones que se publican en el $B O E$ dentro del apartado "Disposiciones Generales", pero ha de tenerse en cuenta que en ocasiones existen verdaderos reglamentos publicados fuera de este apartado. Así, un Real Decreto tan importante como el que delega atribuciones del Consejo de Ministros en una Comisión Delegada del Gobierno (RD 557/1989, de 19 de mayo), publicado en el $B O E$ del 23 de mayo de 1989 dentro del apartado "Otras disposiciones".

2 EI art. 25.2 de la LRJAE establece lo siguiente: "Cuando la disposición o resolución administrativa dimane de una Comisión Delegada del Gobierno o afecte a varios Departamentos, revestirá la forma de Orden del Ministro competente o de la Presidencia del Gobierno, dictada a propuesta de los Ministros interesados...". Pero en la práctica hay que investigar en cada caso si la Orden en cuestión ha sido acordada por la Comisión Delegada del Gobierno, por el ministro firmante, por dos o más ministros "Previa aprobación de la Comisión Delegada" o de cualquier otra forma concordada (así, por ejemplo, una Orden Ministerial de 10 de marzo de 1981 sobre tarifas telefónicas dice dictarse por el ministro uprevia 
complicado saber si la Orden es propiamente ministerial o de Comisión Delegada del Gobierno ${ }^{3}$. El número total de Órdenes ministeriales publicadas en el $B O E$, por su parte, se aproxima a las 8.500 anuales, unas dos mil más que el de Resoluciones, Instrucciones y Circulares.

- Al margen de la LRJAE existen otras disposiciones llamadas "Órdenes acordadas en Consejo de Ministros", similares a los Reales Decretos pero sin la firma regia, y lo que es peor, frecuentemente publicadas mediante Orden Ministerial o simple Circular que se limitan a uponer en conocimiento" dicho acuerdo ${ }^{4}$, con grave quebranto, no ya de la jerarquía jurídica de las disposiciones sino de la propia seguridad jurídica.

- Existen órdenes que podríamos llamar "superministeriales": aquellas en las que el Titular de un Departamento da instrucciones a los demás ministros, como sucede por ejemplo con las de Economía y Hacienda sobre "normas para la elaboración de los Presupuestos Generales del Estado" ${ }^{5}$.

- Por exigencia de la Ley de Procedimiento Administrativo, existen también Órdenes Ministeriales que sólo pueden dictarse "previa autorización de la Presidencia del Gobierno" 6 (desde 1983, del ministro para

autorización" de la Comisión Delegada de Asuntos Económicos ¿es esto una Orden de Comisión? Lo grave de la situación es que tales órdenes son jerárquicamente superiores a las de los ministros, cuando resulta imposible muchas veces saber quién es el autor de la disposición y por tanto el verdadero rango de la disposición.

3 El problema es serio, ya no se trata sólo de aclarar cuál es su rango jerárquico (porque ciertamente son muy infrecuentes los conflictos entre Orden de Comisión Delegada y Orden Ministerial) sino ante quién pueden recurrirse: de acuerdo con la Ley Orgánica del Poder Judicial, la Sala de lo Contencioso-administrativo del Tribunal Supremo conocerá en única instancia de los recursos contra actos o disposiciones emanadas del Consejo de Ministros o de las Comisiones Delegadas del Gobierno (art. 58. $1^{\circ}$ ); mientras que la Sala de lo Contencioso-administrativo de la Audiencia Nacional conoce en única instancia de los recursos contra disposiciones o actos emanados de los ministros (art. 66).

4 Hay casos verdaderamente complicados, como aquella célebre Resolución de una Dirección General que daba a conocer un acuerdo del Consejo de Ministros por el cual se derogaba una Orden Ministerial (ver J.L. VILLAR PALASi: El mito y la realidad en las disposiciones aclaratorias. Madrid, 1965, pág. 55).

5 Entre otras, las Órdenes de 15 de marzo de 1979, 9 de mayo de 1980, 8 de junio de 1981 y 1 de marzo de 1985, todas del Ministerio de Hacienda.

$6 \quad$ Art. 2 LPA de 17 de julio de 1958. 
las Administraciones Públicas ${ }^{7}$, lo cual complica aún más las cosas, pues es un ministro el que autoriza a otro a dictar una Orden Ministerial) ${ }^{8}$.

- Existen Órdenes Ministeriales "concertadas" entre dos o más Ministerios (las dicta un ministro "oído" o "previo acuerdo" con el otro).

- Pese a que la Constitución exceptúa del refrendo ciertos actos del Rey, de hecho todos los Reales Decretos son refrendados, incluso aquellos que según la Constitución no necesitan refrendo (art. 56.3 que excluye de la exigencia de refrendo los supuestos del 65.2) ${ }^{9}$.

- Se desnaturaliza de tal forma la institución del refrendo que con frecuencia el refrendante no es tampoco el responsable de la medida dictada porque no procede de su voluntad sino de la voluntad de un tercero, como sucede con el Real Decreto de nombramiento de Presidente de una Comunidad Autónoma, refrendado por el Presidente del Gobierno, o con el refrendo de la sanción regia de las leyes, que corresponde también al Presidente del Gobierno en vez de al Presidente del Congreso, o también con los Reales Decretos de nombramiento o cese de magistrados y jueces por decisión del Consejo General del Poder Judicial, pero con el refrendo del ministro de Justicia.

3. La situación que acabo de describir, algo caótica como puede comprobarse, es sin embargo perfectamente explicable por razones históricas que conviene conocer para después proponer los cambios pertinentes.

Ya antes del inicio del constitucionalismo era una práctica habitual que los ministros ejerciesen poderes regios sin la autorización -a veces ni el simple conocimiento- del Monarca mediante las llamadas «Reales

7 Art. 7 de la Ley 10/1983, de 16 de agosto y art. 3.2 del Real Decreto 1519/1986, de 25 de julio.

8 Entre otras muchas, la OM de Transportes y Comunicaciones de 29 de enero de 1979 ( $B O E$ de 1 de febrero). El mismo día se publica un Real Decreto de idéntico contenido referido a otro Ministerio y con una redacción casi idéntica lla autorización previa del Presidente del Gobierno):

9 Así, los Reales Decretos 67, 68, 69 y 70/1988, todos ellos de 19 de enero, sobre nombramientos y ceses de miembros de la Casa del Rey. Sólo se diferencian de los demás Reales Decretos en que no figura en la redacción la mención a la deliberación del Consejo de Ministros. 
Órdenes", que no eran sino decisiones personales de los Secretarios de Estado y del Despacho amparadas en la autoridad regia: "De orden del Rey comunico a Vd. que S. M. ha decidido ...). Y esta situaclón no cambió con el paso del Antiguo Régimen al constitucionalismo, ya que el principio de la separación de poderes aceptaba la ficción de que en cada poder, especialmente en el Ejecutivo, existe una voluntad única. Como por otra parte, todas nuestras Constituciones decimonónicas encomendaban al Rey el Poder Ejecutivo ${ }^{10}$, nada tiene de extraño que siguiesen existiendo Reales Órdenes, es decir, que las decisiones de los ministros se amparasen siempre en la voluntad del Monarca.

Es importante retener este dato: como se suponía una voluntad única en el seno del Ejecutivo, ninguna Constitución histórica española se ha preocupado de delimitar competencias, funciones, ni jerarquía alguna entre los órganos integrados dentro de dicho poder. Se consideró que el gran caballo de batalla en estos temas era el sistema de responsabilidad del Gobierno: sólo ante el Rey, doble confianza o sólo ante las Cortes.

También resulta curioso comprobar que hasta 1931 no aparecen las primeras Órdenes Ministeriales, es decir, se consideró hasta entonces que toda disposición emanada de los órganos integrados en el Ejecutivo necesita legitimarse amparándose en la autoridad regia, por ser el Rey formalmente el único titular del Poder Ejecutivo, mientras que la Constitución de 1978, pese a reconocer explícitamente que corresponde al Gobierno y no al Rey ula función ejecutiva y la potestad reglamentaria» (art. 97), sigue manteniendo la ficción de los Reales Decretos («A propuesta del Ministro de ...y previa deliberación del Consejo de Ministros... DISPONGO»).

4. Frente a la situación actual, que como vemos se explica fácilmente por razones históricas y por la conservación de fórmulas constitu-

10 En la Constitución de 1812 se decía: "La potestad de hacer ejecutar las leyes reside en el Rey" (art. 16). Esta misma frase se repetirá después en todas las constituciones monárquicas que siguieron a la de Cádiz: Constitución de 1837 (art. 45), de 1845, (art. 43), de 1856, (art. 49), de 1869, (art. 69), 1876 (art. 50). En definitiva, mientras la función legislativa podía ser considerada como compartida entre el Rey y las Cortes, nunca se cuestionó, en los Textos constitucionales, que la función ejecutiva era exclusiva del Rey. Si de iure esto es indudable, es sabido que de facto durante el siglo $\mathrm{XIX}$ el poder ejecutivo se va desplazando lentamente desde el Monarca al Consejo $y$ a los ministros individualmente considerados. 
cionales e incluso legislativas totalmente anacrónicas e inoperantes, propongo una regulación rigurosa y coherente de estas materias. En definitiva, que la jerarquía de las disposiciones dictadas por los diversos órganos del Gobierno y la Administración se establezca de acuerdo con la jerarquía orgánica real existente en el seno del poder ejecutivo, de acuerdo con lo que la Constitución establece ya al respecto, con alguna pequeña precisión que ayudaría a perfilar mejor el papel que corresponde a cada órgano en nuestro sistema político.

Esto podría conseguirse, a mi juicio, con las siguientes medidas:

1. Separando nítidamente las funciones regias de las propiamente ejecutivas. No se trata de crear ahora espacios de poder para el Monarca, sino de algo bien distinto: ya que su figura institucional responde a la idea de árbitro y moderador de los poderes del Estado, colocándose por encima, o al menos, al margen de los demás poderes, seria conveniente que sólo se aprueben por medio de Real Decreto, es decir, que sólo precisen la firma regia aquellas decisiones políticas que afectan al regular funcionamiento del resto de los poderes públicos, tanto si proceden del Gobierno como si proceden de otros órganos constitucionales, pero no el simple ejercicio de potestades administrativas, tales como la reglamentaria y otras estrictamente gubernativas .

Como complemento, estas disposiciones firmadas por el Rey deben ser refrendadas por el titular del órgano político (su presidente si es un órgano colegiado) que ha sido autor verdadero de la misma, precisamente para preservar la pureza de la institución del refrendo: el Rey no es responsable porque lo es el refrendante, por tanto que el refrendante sea el que ha tomado la decisión y no un tercero. En conclusión, sería preciso aumentar la lista de personas legitimadas para refrendar los actos del Rey (art. 64.1 CE).

2. En consecuencia, debe existir un tipo de disposición específica y exclusiva del Consejo de Ministros en la que éste ejerce sus potestades, sin intervención regia alguna, ni siquiera puramente formal. Si la potestad reglamentaria, por ejemplo, está atribuida ya por la Constitución al Gobierno ¿qué necesidad hay de ampararse en la voluntad regia («dispongo») $y$ exigir su firma?

3. Las Órdenes Ministeriales, como es lógico, deben mantenerse para que los ministros ejerzan sus competencias propias, pero parece imprescindible que entre el Decreto del Gobierno y la Orden Ministerial exista una categoría intermedia que debería aparecer firmada siempre por el 
Presidente en uso de su propia competencia de «dirección de la acción del Gobierno" $y$ de "coordinación de las funciones de los ministros» (art. 98.2).

Estas "órdenes de la Presidencia», como por cierto se las llamó en otros momentos históricos, abarcarian a todas las figuras actuales situadas de una forma u otra entre el Decreto y la Orden Ministerial, es decir:

- Las Órdenes acordadas en Consejo de Ministros.

- Las Órdenes de Comisión Delegada del Gobierno.

- Las Órdenes de un ministro que vinculan a otro u otros.

- Las Órdenes concertadas entre dos o más Ministerios.

4. ${ }^{\circ}$ Por consiguiente la jerarquía de las disposiciones que proponemos sería esta:

- Los "Decretos del Gobierno". Firmados por el Presidente haciendo constar que se trata de un acuerdo del Consejo de Ministros y no de una decisión personal suya.

- Las "Órdenes de la Presidencia del Gobierno". Firmadas también por el Presidente pero en uso de su autoridad propia sobre los demás miembros del Gobierno.

\section{- Las Órdenes ministeriales.}

- Las disposiciones de órganos inferiores, jerarquizadas como es lógico entre sí, y que deberían denominarse "Órdenes de Subsecretaria", "Ordenes de Dirección General», etc., mejor que Resoluciones, Instrucciones y Circulares como ahora, para evitar la confusión que esta variedad de nombres puede originar.

5. Sólo serian formalizados como Reales Decretos, por tanto los siguientes actos y decisiones políticas: nerales.

- La disolución de las Cortes y la convocatoria de elecciones ge- 
- La convocatoria de referéndum.

- El nombramiento y cese de los titulares de los órganos superiores: del Gobierno, del Tribunal Constitucional, del Consejo General del Poder Judicial y además los de Presidentes de Comunidades Autónomas. También, el nombramiento y cese del Presidente del Consejo de Estado y del Tribunal de Cuentas, del Fiscal General del Estado e incluso del Defensor del Pueblo, puesto que ya no sería el Rey quien nombrara (ni siquiera formalmente) sino quien proclama solemnemente que tal nombramiento se ha producido por parte del órgano constitucional legitimado para hacerlo.

Por lo demás, convendría mantener la firma regia en la promulgación de las leyes y en la manifestación del consentimiento del Estado para obligarse internacionalmente mediante tratados. En este sentido, de considerarse que la ley es uno de los actos políticos que, por su importancia para la vida del Estado deben solemnizarse con la firma regia (como creo que debe ser y como de hecho ocurre en todo Estado monárquico excepto en Suecia, donde las leyes se publican autorizadas por el Primer Ministro ${ }^{11}$, entonces sería lógico que también lo fuesen las normas del Ejecutivo que tengan dicho rango: los Decretos-leyes y los Decretos-legislativos, pero no como decisiones aparentemente regias, sino como forma de dar mayor solemnidad a la decisión política de un órgano constitucional considerada de especial trascendencia ${ }^{12}$. Pero no sería propio hablar ya, en todos estos casos, de sanción regia sino de simple promulgación, es decir, declaración solemne de la existencia de la norma, con total independencia de la voluntad del Monarca.

5. Queda aún por demostrar que los cambios propuestos deban ya encontrarse en la propia Constitución o si no bastaría con dejar al legislador un amplio margen de libertad al respecto.

11 Art. 7 del Capítulo 7 de la Constitución sueca tras la reforma de 1974.

12 En este sentido, la redacción actualmente utilizada en la fórmula para la sanción regia de las leyes debería modificarse, pues no parece ya adecuado que diga: "Las Cortes han aprobado y Yo vengo en sancionar", sino acaso algo así como "Al haber sido aprobada por las Cortes vengo en promulgar" la presente ley. Lo mismo debería suceder con los Decretos-leyes y Decretos legislativos, que a mi juicio son propiamente leyes con procedimiento peculiar de aprobación y no Decretos a los que excepcionalmente se otorga rango superior. 
Dos críticas principales pueden hacerse a la propuesta de constitucionalizar esta cuestión: $1 .^{a}$ La falta de precedentes en el panorama comparado, particularmente en los Estados monárquiicos, y 2. ${ }^{a}$ La excesiva rigidez que supondría impedir que sea el Gobierno de turno o el Parlamento quien regule una cuestión interna de uno de los poderes.

A. Si echamos una mirada al Derecho comparado - no digamos nada a nuestra propia Historia constitucional- podemos concluir que no es normal encontrar Constituciones que recojan una ordenación de las fuentes procedentes del Ejecutivo, precisamente por la razón antes mencionada: porque en el Gobierno y la Administración se supone una voluntad única. Tàmbién hay que reconocer que las Constituciones de las Monarquías parlamentarias europeas, aun las más modernas, (con la excepción de Suecia tras la reforma de 1974), mantienen la confusión de funciones regias y gubernativas, de manera que, de una forma $u$ otra, se sigue creyendo que el Rey es, además de Jefe del Estado, cabeza del Ejecutivo ${ }^{13}$. Sólo en la Constitución de Mónaco, relativamente reciente, de 1962, es posible encontrar preceptos semejantes al que aquí se propone ${ }^{14}$.

Frente a esta realidad quiero recordar que una Constitución como la nuestra, por carecer de la auctoritas que otorga la tradición y la antigüedad a otras Constituciones, debe buscarla sólo en la capacidad de convertirse en un instrumento lo más perfecto posible - desde un punto de vista técnico- para dar respuestas a los problemas reales de la sociedad. En este sentido resulta bastante claro que las Constituciones modernas dedican, cada vez más, un número importante de preceptos a regular el tema de las fuentes. Este fenómeno es de prever que continuará en los próximos años, pues uno de los problemas capitales de Derecho constitucional es hoy el de la regulación de las fuentes y mucho menos ya las relaciones del Rey con el Gobierno, por ejemplo.

B. Aun aceptando que sea un tema importante algo descuidado

13 Véanse al respecto los arts. 29, 63, 65 y 67 de la Constitución de Bélgica; arts. 3, 12, 13 y 14 de la Constitución de Dinamarca; arts. 56, 57 y 86 de la Constitución de Holanda; art. 10 de la Constitución de Liechtenstein; arts. 33 y 36 de la Constitución de Luxemburgo; arts. 3 y 43 de la Constitución de Mónaco; arts. 3 y 17 de la Constitución de Noruega.

14 En sus arts. 45 a 48 se establece qué tipos de disposiciones existirán en el Ejecutivo, quién las firma y refrenda y sus relaciones. Más aún, se dice qué materias se deben regular por Real Decreto (Ordennance Souveraine) y por Orden Ministerial. 
hasta hoy ¿por qué incluirlo en la propia Constitución? Pues porque se trata de un problema de poder: qué potestades tiene el Consejo de Ministros, cuáles el Presidente y cuáles los otros miembros del Gobierno. Se trata en realidad de configurar el cometido y la función constitucional que corresponde a estos órganos y por tanto en cierto modo los perfiles mismos del poder al que pertenecen. $Y$ esto no debe quedar en manos del legislador: del mismo modo que la configuración de la estructura esencial de los otros poderes no se deja nunca en manos de la ley, sino que son establecidos por la propia Constitución. Cada nuevo Presidente del Gobierno (en su caso, cada nueva mayoría parlamentaria), tendrá libertad para establecer cuántos Ministerios debe haber, sus denominaciones y competencias, pero no se debe dejar en sus manos decidir cuál deba ser la estructura misma de los órganos superiores del Ejecutivo. Y no basta con que la Constitución contenga una regulación indirecta de estos temas con la simple referencia a que el Presidente es quien propone al Rey el nombramiento y cese de los Ministros. De todas formas téngase en cuenta que la rigidez no sería excesiva pues el Texto constitucional no establecería qué materias deben regularse por Decreto y cuáles por Orden Presidencial o Ministerial. Esto sería regulado por Ley.

6. En definitiva, los cambios propuestos en el Texto constitucional serían los siguientes.

- En el art. 62 ("Corresponde al Rey:») suprimir la frase del apartado f) que dice: «Expedir los decretos acordados en Consejo de Ministros"s.

- El art. 64 quedaría redactado de la siguiente forma:

«1. Todo Real decreto será firmado por el Rey y refrendado por quien lo propone o en el caso de que sea un órgano colegiado, por su Presidente.

2. Las normas estatales con rango de ley serán promulgadas por el Rey con el refrendo del Presidente del Congreso o del Presidente del Gobierno según quien sea su autor.

3. De los actos del Rey serán responsables las personas que los refrenden". 
- Se añade un nuevo apartado al art. 103 entre los números 2 y 3 actuales en los siguientes términos: «3. Las disposiciones administrativas se ajustarán a la siguiente jerarquía: Primero: Decretos del Gobierno; Segundo: Órdenes de la Presidencia del Gobierno; Tercero: Órdenes ministeriales; Cuarto: Órdenes de autoridades inferiores según su respectiva jerarquía orgánican. 